\title{
A Validated Inductively Coupled Plasma-Optical Emission Spectrometry (ICP-OES) Method to Estimate Free Calcium and Phosphorus in In Vitro Phosphate Binding Study of Eliphos Tablets
}

\author{
Venkata Vivekanand Vallapragada ${ }^{1,2^{*}}$, Gopichand Inti ${ }^{1}$, J. Sri Ramulu ${ }^{2}$ \\ ${ }^{1}$ Invagen Pharmaceutical Inc, Hauppauge, USA \\ ${ }^{2}$ Department of Chemistry, Sri Krishna Devaraya University, Anantapur, India \\ E-mail: vvviveka@yahoo.com \\ Received June 24, 2011; revised July 25, 2011; accepted August 2, 2011
}

\begin{abstract}
An ICP-OES method has been developed to estimate Calcium and Phosphorous in In vitro phosphate binding study of Eliphos Tablets. The method is selective and is capable of detecting calcium and phosphorous in the presence of other trace elements. The method has been validated using RF power of 1500 watts, plasma flow of $15 \mathrm{~L} / \mathrm{min}$, Nebuliser flow of $0.8 \mathrm{~L} / \mathrm{min}$ and plasma view at radial mode for calcium and axial mode for phosphorus. The wavelength was monitored for calcium and phosphorous at $317.933 \mathrm{~nm}$ and $213.677 \mathrm{~nm}$ respectively. The method has been validated in terms of specificity, precision, linearity, accuracy, limit of quantification and ruggedness. The In vitro binding studies were performed for Eliphos Tablets at eight different phosphate concentrations by incubating at $37.0^{\circ} \mathrm{C}$ and analysis was performed using the validated method to estimate free calcium and phosphorus. The objective of the study is to provide an alternate In vitro method to estimate the binding capacity of calcium acetate tablets to avoid the expensive in-vivo bio clinical studies.
\end{abstract}

Keywords: ICP-OES, Phosphate Binding Study, Quantification, Eliphos Tablets, Free Calcium

\section{Introduction}

Calcium Acetate is the Active ingredient in Eliphos Tablets ${ }^{\mathrm{TM}}$ and is indicated for haemodialysis and peritoneal dialysis. In kidney disease, blood levels of phosphate may raise leading to bone problems. Calcium Acetate binds phosphate in the diet to lower blood phosphate levels. This medication is used in kidney disease to control blood phosphate.

Phosphorus is an essential element necessary for the normal function of human body, required for skeletal construction and synthesis of DNA, proteins and adenosine Triphosphate. In healthy individuals, serum phosphorus concentrations are maintained between 2.5 and $4.5 \mathrm{mg} / \mathrm{dL}$ through diet and renal excretion. In renal insufficiency, phosphorus excretion declines and hyperphosphatemia develops. The body's compensation mechanisms cause secondary hyperparathyroidism and renal osteodystrophy.
Phosphate binders provide an effective means for managing serum phosphate. Commercially available phosphate binders include calcium carbonate, calcium acetate and rarely aluminum hydroxide. Calcium carbonate's benefits are seen over a narrow gastric $\mathrm{pH}$ range, thereby limiting the drug's utility. Calcium acetate is effective over a wide $\mathrm{pH}$ range [1,2]. Because of aluminum's known toxicities, aluminum based phosphate binders have a limited place in therapy. Up to this time, no biological function has been attributed to this metal, and, more importantly, aluminum accumulation in tissues and organ results in their dysfunction and toxicity. Aluminum causes an oxidative stress within brain tissue. Since the elimination half-life of aluminum from the human brain is 7 year, this can result in cumulative damage via the element's interference with neurofilament axonal transport and neurofilament assembly. Some experts believe it plays a role in leading to the formation of Alzheimer like neurofibrillary tangles [3-11]. 
The general analytical techniques employed for the inorganic metal impurities include titration, ion chromatography, capillary electrophoresis and inductively coupled plasma (ICP). Among the above-said techniques, ICP is a versatile tool for detection and quantification of elements in accurate manner. The ICP technique is based on atomic spectrometry. Most specifically, the ICP-OES is emission spectrometric technique that exploits the fact that excited atoms emit energy at a given wavelength as the electrons return to their ground state. A given element emits energy at specific wavelengths peculiar to its chemical character. The intensity of the energy emitted at that wavelength is proportional to the amount of that element in the analyzed sample.

ICP-OES has additional advantages over the other techniques in terms of detection limits as well as speed of analysis. In ICP-OES sample experiences temperatures estimated to be in the vicinity of $10,000 \mathrm{~K}$. This results in atomization and excitation of even most refractory elements with high efficiency so that detection limits for these elements with ICP-OES can be well over and order of magnitude better than the corresponding values of other techniques. The limit of quantitation values of most of the elements in ICP-OES in parts per million and even parts per billion. In number of analytical applications speed can be an important factor. Those advocating simultaneous ICP-OES regard it is the only method worth considering for this task because it is so much analyses sample in minutes is only fast enough if the sample preparation time takes only a few minutes $[12,13]$. In other technique like ion chromatography, capillary electrophoresis stabilization is a time taking process and sensitivities are low when compared with ICP-OES. The titration methods are not accurate especially while estimating the elements at lower concentrations and also errors could be expected.

We have come across few publications regarding influence of $\mathrm{pH}$ on In vitro disintegration of phosphate binders. However we did not find any publication giving details determining the calcium and phosphorus in In vitro phosphate binding study of calcium acetate tablets in the open literature. The phosphate binders disintegration is a pH dependant as well as formulation dependant. It was found that disintegration in simulated gastric fluid and distilled water yielded a higher passing rate than that of intestinal fluid. The percentage of products that passed the study disintegration test in distilled water, gastric fluid, and intestinal fluid were $80 \%, 80 \%$ and $73 \%$ respectively [14-18]. This paper describes not only the methodology and validation it also includes the study of In vitro phosphate binding of Eliphos Tablets $667 \mathrm{mg}$ by Inductively Coupled Plasma. Free Calcium and Free Phosphorus in the supernatant solution was determined in eight different phosphate concentrations to estimate the binding assay.

\section{Experimental}

\subsection{Chemicals}

Calcium Acetate was obtained from Kemira chemsolutions b.v (Netherlands). Sodium Phosphate tribasic $\left(\mathrm{Na}_{3} \mathrm{PO}_{4}\right)$ obtained from Spectrum Chemicals (USA). Deionised water was obtained from an in-house TOC water system (Sievers, USA). Eliphos Tablets are purchased from Amsterdam pharmacy, New York and manufactured by Hawthorn pharmaceuticals Inc (USA).

\subsection{Equipment}

A Perkin Elmer Inductively coupled Plasma system equipped with Optical Emission Spectrophotometer and system controlled through Win Lab32 software. The incubator used for the experiment is Max Q 4000 of Thermo Scientific.

\subsection{Sample Preparation}

A stock solution of Calcium Acetate was prepared 4.733 $\mathrm{mg} / \mathrm{ml}(29.89 \mathrm{mM})$ by dissolving the appropriate amount of the calcium acetate in deionised water. Sodium Phosphate was not prepared as stock preparation and weighed separately depending on validation experiment.

\subsection{Method Development}

The main objective of the study is to develop a suitable ICP-OES method to quantitate calcium and phosphorus in the presence of placebo and other matrix.

The placebo contains PEG 8000, Sodium Lauryl Sulfate and Crospovidone. The other matrix means sodium phosophate buffer in which sodium is possible interference in the development. During the method development calcium standard was prepared at working concentration $0.04733 \mathrm{mg} / \mathrm{mL}(0.2989 \mathrm{mM})$ in deionised water. The calcium standard was monitored at different possible emission lines of $317.933 \mathrm{~nm}, 315.887 \mathrm{~nm}$, $393.366 \mathrm{~nm}, 396.847 \mathrm{~nm}, 422.673 \mathrm{~nm}$ and $227.546 \mathrm{~nm}$ [19-22]. In among these emission lines at applied target $\mathrm{RF}$ power of $1500 \mathrm{~W}$ the responses for calcium were evaluated. The response of calcium is very high at emission line of $317.933 \mathrm{~nm}$ and moreover the baseline found to be good, comparatively at other emission lines of calcium. The calcium response was even good at radial view mode. The possible interference with phosphorus, sodium and placebo related interference were not observed at 
this emission line.

The phosphorus standard was monitored at different possible emission lines of $213.617 \mathrm{~nm}, 214.914 \mathrm{~nm}$, $178.221 \mathrm{~nm}$ and $177.434 \mathrm{~nm}$ by aspirating the solution at lowest buffer solution concentration $(0.02817 \mathrm{mM})$. The method was optimized at lowest phosphate concentration during method development. The phosphate concentration is low and to get better sensitivity view mode was selected as Axial. In axial, plasma views down the central channel of the plasma and collects all the analyte emission over the entire length of the remaining plasma after the shear gas. This region is much larger than that viewed by normal radial or normal side on ICP resulting higher intensity for phosphorus.

\subsection{ICP-OES Conditions}

Calcium:

The RF power was used 1500 watts, Plasma flow was used $15 \mathrm{~L} / \mathrm{min}$, Auxillary Flow was kept at $0.2 \mathrm{~L} / \mathrm{min}$, Nebuliser Flow was kept at $0.8 \mathrm{~L} / \mathrm{min}$, Pump Rate was kept at $1.5 \mathrm{ml} / \mathrm{min}$, Calcium was monitored at wavelength of 317.933 and plasma view was in Radial mode.

Phosphorus:

The RF power was used 1500 watts, Plasma flow was used $15 \mathrm{~L} / \mathrm{min}$, Auxillary Flow was kept at $0.2 \mathrm{~L} / \mathrm{min}$, Nebuliser Flow was kept at $0.8 \mathrm{~L} / \mathrm{min}$, Pump Rate was kept at $1.5 \mathrm{ml} / \mathrm{min}$, Phosphorus was monitored at wavelength of 213.617 and plasma view was in axial mode.

\subsection{Validation of the Method}

\subsubsection{Specificity}

The International Conference on Harmonisation defines specificity as the ability to assess unequivocally the analyte in the presence of components that may be expected to be present, such as impurities, degradation products and placebo matrix. Calcium Acetate solution at $0.04733 \mathrm{mg} / \mathrm{mL}$ solution (0.2989 mM) and placebo sample solution was separately aspirated at $317.933 \mathrm{~nm}$ into ICP-OES to check the interference of any other elements at that particular wavelength.

The $5.6334 \mathrm{mM}$ Sodium phosphate solution (3.08 $\mathrm{mg} / \mathrm{ml}$ ) was prepared and aspirated into ICP-OES at $213.617 \mathrm{~nm}$ along with placebo solution to evaluate the interference of any other elements or matrix.

\subsubsection{Precision}

Precision of the method is the degree of agreement among the individual test results when the procedure is applied repeatedly to multiple samplings of a homogenous sample. The precision of the method was checked by analyzing five replicates of Calcium Acetate and Sodium
Phosphate solutions at working concentrations and the \%RSD found to be with in the specification. Refer Table 1.

\subsubsection{Linearity}

The linearity of an analytical method is its ability to elicit test results that are directly, or by a well defined mathematical transformation, proportional to the concentration of analyte in samples within a given range [23].

Linearity was evaluated by determining six working solutions for Calcium ranging from 10\%, 20\%, 50\%, $80 \%, 100 \%$, and $150 \% \mathrm{w} / \mathrm{v}$ with respect to working concentration of $0.0473 \mathrm{mg} / \mathrm{ml}(0.2989 \mathrm{mM})$. The above solutions were prepared from stock solution of Calcium Acetate. Each solution was aspirated five times. The mean responses recorded for calcium was plotted against concentration. The correlation coefficient for calcium was found to be 0.9995 which indicated good linearity.

Linearity was evaluated by determining nine working solutions for sodium phosphate tribasic ranging from $0.014085 \mathrm{mM}, 0.02817 \mathrm{mM}, 0.14084 \mathrm{mM}, 0.28167 \mathrm{mM}$, $1.12668 \mathrm{mM}, 1.97169 \mathrm{mM}, 2.8167 \mathrm{mM}, 5.6334 \mathrm{mM}$ and $8.450103 \mathrm{mM}$. Each solution was aspirated five times. The mean responses recorded for phosphorus were plotted against concentration. The correlation coefficient for calcium was found to be 0.9999 which indicated good linearity.

The Calibration equations for calcium and phosphorous were round to be $y=29317644 x-9591.581$ and $y=$ 265323.166 + 9502.654 respectively. Refer Figures 1 and $\mathbf{2}$ for the Linearity plots for calcium and phosphorus.

\subsubsection{Accuracy}

Calcium Acetate sample solutions were spiked with placebo at different concentrations i.e. $60 \%$, 80\%, 100\%, $120 \%$ and $140 \%$ with respect to working concentration of $0.04733 \mathrm{mg} / \mathrm{ml}(0.2989 \mathrm{mM})$. Each spiked solution

Table 1. Precision results of calcium at emission line of $317.933 \mathrm{~nm}$ and phosphorus at emission line of $213.677 \mathrm{~nm}$.

\begin{tabular}{ccc}
\hline Aspirations & $\begin{array}{c}\text { Peak intensity } \\
\text { of calcium }\end{array}$ & $\begin{array}{c}\text { Peak intensity } \\
\text { of phosphorus }\end{array}$ \\
\hline 1 & 125322.4 & 1502730.0 \\
2 & 126382.7 & 1506216.4 \\
3 & 128442.8 & 1508620.5 \\
4 & 130034.5 & 1506005.3 \\
5 & 131995.7 & 1498419.3 \\
Average & 128435.6 & 1504398.3 \\
\%RSD & $2.10 \%$ & $0.26 \%$ \\
\hline
\end{tabular}




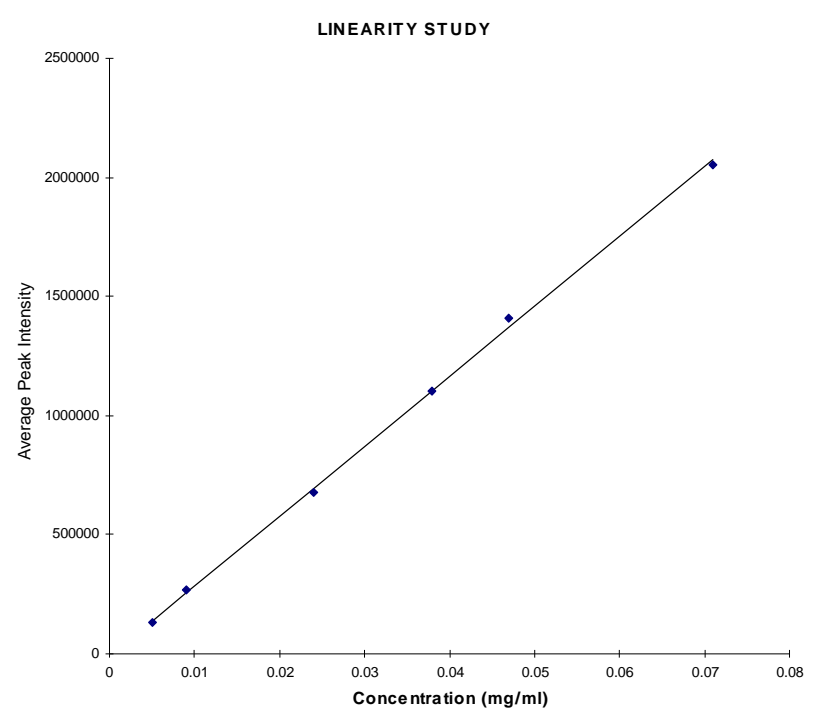

Figure 1. Linearity graph of Calcium at emission line of $317.933 \mathrm{~nm}$, plotted concentration on $X$-axis versus average peak intensity on $\mathrm{Y}$-axis.

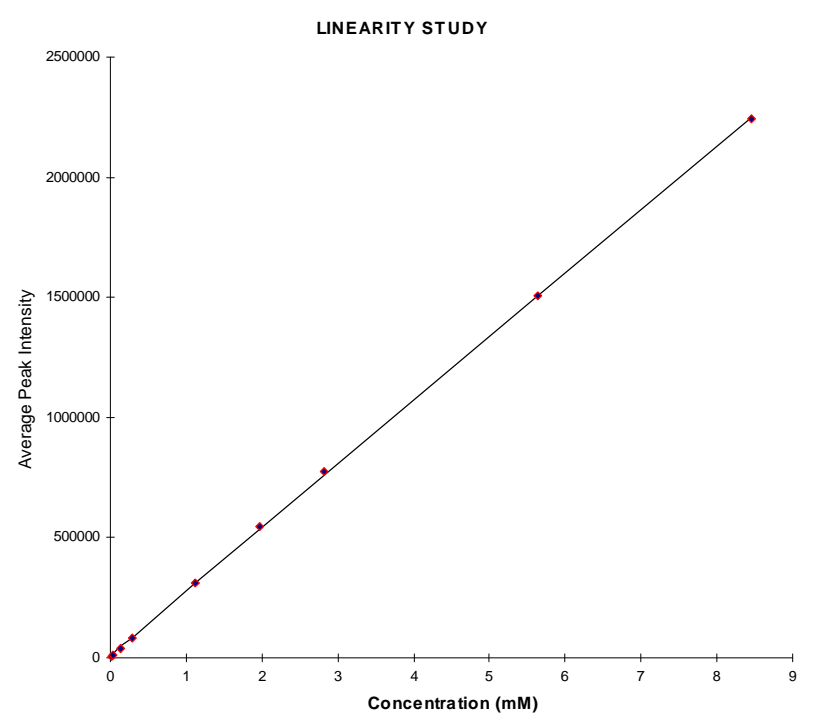

Figure 2. Linearity graph of Phosphorus at emission line of $213.677 \mathrm{~nm}$, plotted concentration on $\mathrm{X}$-axis versus average peak intensity on $\mathrm{Y}$-axis.

was prepared in triplicate and aspirated. The recovery of calcium in the presence of the placebo was calculated against the calcium standard prepared at $0.04733 \mathrm{mg} / \mathrm{ml}$ (0.2989 mM). Recovery of calcium ranged from $98.3 \%$ $101.1 \%$. The phosphorous recovery in the presence of calcium acetate is not possible since phosphorous binds to calcium and forms calcium phosphate. The phospho- rous accuracy has not been studied for this reason. Refer Table 2 for recovery values.

\subsubsection{Limit of Quantification}

The limit of quantification of an individual analytical procedure is the lowest amount of analyte in a sample, which can be quantitatively determined with suitable precision and accuracy.

The precision of the method for calcium at limit of quantification was checked by analyzing six replicates prepared at concentration of $1.75 \mu \mathrm{g} / \mathrm{ml}(0.011 \mathrm{mM})$ and calculating the percentage relative standard deviation.

The precision of the method for phosphorus at limit of quantification was checked by analyzing six replicates prepared at concentration of $0.014085 \mathrm{mM}$ phosphate buffer solution and calculating the percentage relative standard deviation.

\subsubsection{Ruggedness}

The ruggedness of a method was defined as degree of reproducibility of results obtained by analysis of the same sample under variety of normal test conditions such as different labs, different analysts, different instruments, and different lots of reagents. The recovery levels tested in Section 2.6.4 (laboratory A) were again carried out in laboratory B using a different instrument. The recovery values were found to be comparable.

\section{In Vitro Phosphate Binding Study}

The office of Generic drugs, a division of Food and Drug Administration has recommended the In vitro phosphate binding study of Calcium Acetate Tablets to determine the binding capacity. Phosphorus binding is either a chemical reaction between dietary phosphorous and cation of the binder compound, resulting in the formation of insoluble and hence unabsorbable phosphate compounds or an adsorption of phosphorus ions on the surface of binding particles or a combination of both processes. The operational definition of phosphorus binding varies in the three parts of this study. In theoretical calculations, binding is defined as formation of insoluble solid phosphate. For the in vitro experiments, the amount of phosphorus that did not pass through a millipore filter was regarded as bound by the binder. In this case calcium is a positive ion and phosphate binds to calcium resulting insoluble calcium phosphate. The chemical equation is shown below as reference.

$$
3 \mathrm{Ca}\left(\mathrm{CH}_{3} \mathrm{COO}\right)_{2}+2 \mathrm{Na}_{3} \mathrm{PO}_{4} \longrightarrow \mathrm{Ca}_{3}\left(\mathrm{PO}_{4}\right)_{2}+6 \mathrm{CH}_{3} \mathrm{COONa}
$$

Insoluble form 
Table 2. Percentage recovery of calcium at different concentration levels in the presence of placebo as a part of method validation under accuracy experiment.

\begin{tabular}{ccc}
\hline Concentration level & \% Recovery & Average recovery \\
\hline $60 \%$ Prep-1 & 98.3 & \\
$60 \%$ Prep-2 & 98.3 & \\
$60 \%$ Prep-3 & 98.9 & \\
$80 \%$ Prep-1 & 100.1 & 100.1 \\
$80 \%$ Prep-2 & 99.5 & \\
$80 \%$ Prep-3 & 100.5 & \\
$100 \%$ Prep-1 & 100.3 & \\
$100 \%$ Prep-2 & 100.4 & \\
$100 \%$ Prep-3 & 100.7 & \\
$120 \%$ Prep-1 & 101.1 & 100.9 \\
$120 \%$ Prep-2 & 100.8 & \\
$120 \%$ Prep-3 & 100.7 & 100.3 \\
$140 \%$ Prep-1 & 100.8 & \\
$140 \%$ Prep-2 & 99.4 & \\
$140 \%$ Prep-3 & 100.8 & \\
\hline
\end{tabular}

\subsection{Buffer and Sample Preparations}

\section{Phosphate Buffer Preparation}

Sodium Phosphate buffer solutions were prepared at the concentrations of $0.02817 \mathrm{mM}, 0.14084 \mathrm{mM}, 0.28167$ $\mathrm{mM}, 1.12668 \mathrm{mM}, 1.97169 \mathrm{mM}, 2.8167 \mathrm{mM}$ and 5.6334 $\mathrm{mM}$. The above phosphate buffer solutions $\mathrm{pH}$ were observed 10.0, 10.5, 10.7, 11.0, 11.2, 11.3 \& 11.5 respectively. DI water was also placed in this experiment and considered as a $0.0 \mathrm{mM}$ phosphate buffer.

Transferred $150 \mathrm{ml}$ of each buffer into each 12 incubating flasks, weighed 12 Eliphos tablets and transferred into individual incubating flasks shaked well to dissolve. Twelve Calcium Acetate Tablets were tested at each buffer stage and 96 tablets were used for this experiment. All the samples were then placed on a BOD incubator shaker at $37^{\circ} \mathrm{C}$ for 2 hours to ensure the establishment of phosphate binding equilibrium.

All the samples were removed filtered through $0.45 \mu \mathrm{m}$
Nylon filter. The filtrates were studied to estimate the concentrations of free calcium and phosphate. Some of the filtrate portion used for the analysis of free calcium and other portion used to estimate free phosphate. The filtrates were diluted $1 \mathrm{ml}$ to $100 \mathrm{~mL}$ with deionised water in order to achieve within the range of ICP working concentration for Calcium where as filtrates were used as is with out any further dilutions for phosphate.

\subsection{Optimizing Incubating Time}

To optimize the incubation time four tablets were separately incubated in $5.6334 \mathrm{mM}$ phosphate buffer solution of $150 \mathrm{ml}$ at different intervals like 60 minutes, 90 minutes, 120 minutes and 180 minutes. The binding assay was calculated and found constant from 90 minutes to 180 minutes range. The incubation time has been elected as 120 minutes time for entire study for better precision and accuracy.

\subsection{Standards Preparation}

Calcium Acetate standard was prepared at $0.04733 \mathrm{mg} /$ $\mathrm{mL}(0.2989 \mathrm{mM})$ in deionised water. Before adding the tablets into phosphate buffers some of the portions were separated and used as phosphate standard solutions. Refer the typical ICP spectras for calcium and phosphorus in Figures 3 and 4 respectively.

\subsection{Calculations}

The unbound phosphorus and calcium concentrations remaining in each sample were calculated from individual phosphate buffer standard preparations and calcium standard solutions.

Free phosphorus or Calcium

$$
\frac{\mathrm{Au} \times \mathrm{C}}{\mathrm{As}}
$$

where

$\mathrm{Au}$ is the mean corrected intensity of phosphorus/calcium in sample preparation,

As is the mean corrected intensity of phosphorus/calcium in standard preparation,

$\mathrm{C}$ is the molar concentration of phosphorus/calcium in standard preparation.

$$
\text { \%binding of phosphate }=\frac{\text { Sodium phosphate added }(\mathrm{mM}) \text {-free phosphorus found }(\mathrm{mM})}{\text { Sodium phosphate added }(\mathrm{mM})} \times 100
$$

The phosphate binding was calculated by subtracting free phosphorus found in samples from added sodium phosphate in mM. Divided the result with sodium phos- phate added and multiplied with hundred to convert into percentage. The complete study data was tabulated including the free calcium, free phosphate and binding 
assay of phosphate.

\subsection{Discussion}

The free calcium and free phosphate data clearly indi- cates binding assay at different concentrations of phosphate buffer solutions. Refer Table 3. Calcium Acetate is highly soluble compound. Calcium Acetate dissolves readily thus making all the binder available for reaction. In the case of poorly soluble compounds, however, only

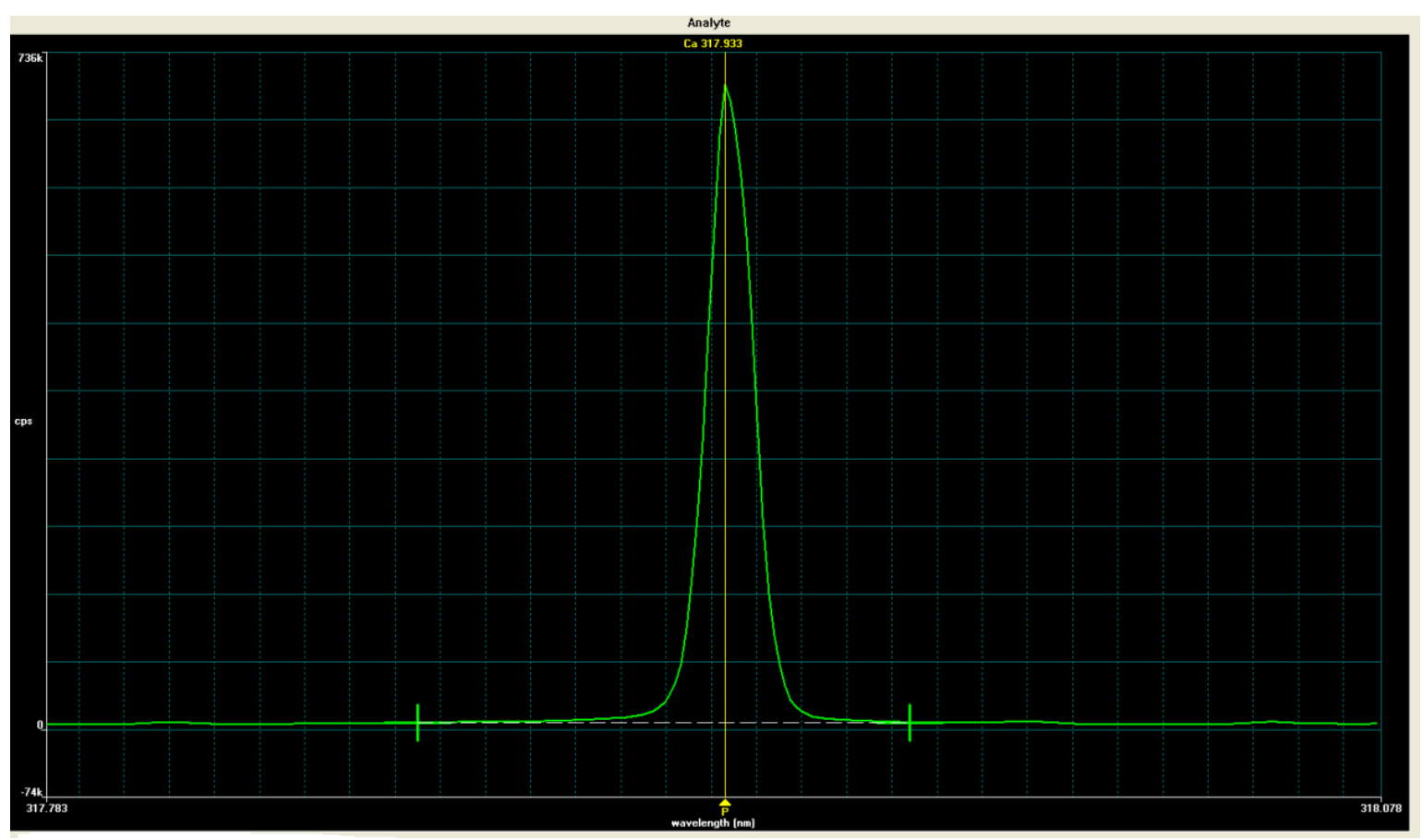

Figure 3. Typical ICP spectra of Calcium standard at working concentration of $0.0473 \mathrm{mg} / \mathrm{ml}(0.2989 \mathrm{mM})$ at emission line of 317.933 nm.

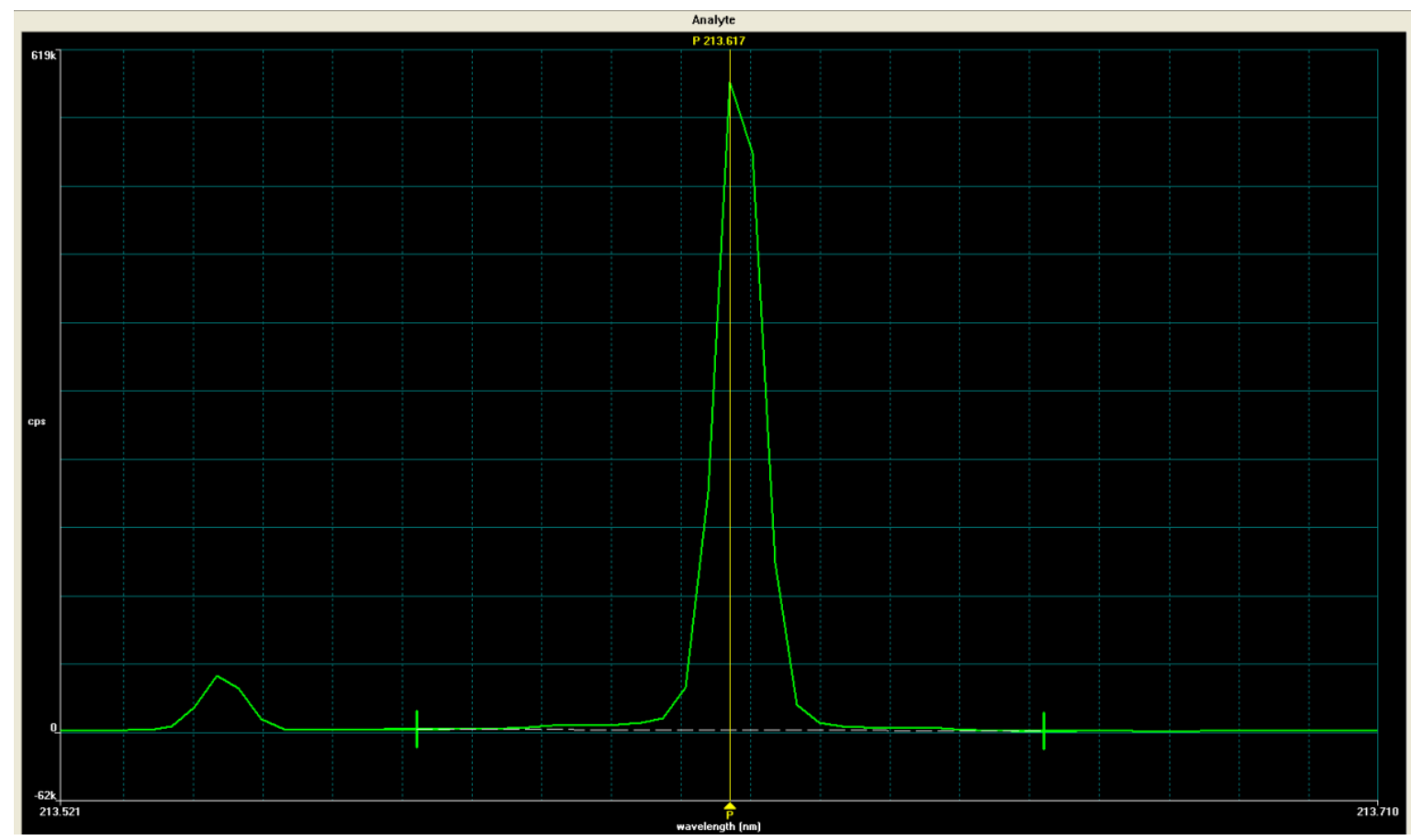

Figure 4. Typical ICP spectra of Phosphorus at concentration of $5.633 \mathrm{mM}$ at emission line of $213.677 \mathbf{~ n m}$. 
Table 3. Average percentage binding data of Twelve tablets at each buffer stage, experimented with RF power of 1500 watts, plasma flow of $15 \mathrm{~L} / \mathrm{min}$, Auxillary flow of $0.2 \mathrm{~mL} / \mathrm{min}$, Nebuliser flow of $0.8 \mathrm{~L} / \mathrm{min}$, plasma view at radial mode for calcium, axial view for phosphorus and wavelength of $\mathbf{3 1 7 . 9 3 3}$ for calcium and $\mathbf{2 1 3 . 6 1 7}$ for phosphorus.

\begin{tabular}{cccc}
\hline Buffer Concentration & Free calcium $(\mathrm{mM})$ & Free phosphate $(\mathrm{mM})$ & \% Binding \\
\hline $0.000 \mathrm{mM}$ buffer & 27.241 & 0.000 & 0.0 \\
$0.028 \mathrm{mM}$ buffer & 27.241 & 0.002 & 93.6 \\
$0.141 \mathrm{mM}$ buffer & 27.473 & 0.009 & 93.3 \\
$0.282 \mathrm{mM}$ buffer & 25.012 & 0.008 & 98.4 \\
$1.127 \mathrm{mM}$ buffer & 22.092 & 0.018 & 99.3 \\
$1.972 \mathrm{mM}$ buffer & 20.494 & 0.014 & 99.7 \\
$2.817 \mathrm{mM}$ buffer & 19.696 & 0.007 & 99.8 \\
$5.633 \mathrm{mM}$ buffer & 16.342 & 0.112 & \\
\hline
\end{tabular}

a small amount slowly gets dissolved. As this small amount of dissolved binder reacts with phosphorus, the concentration of dissolved binder falls, which in turn allows further dissolution. This process continues until equilibrium is reached. It follows that freely soluble compounds would reach equilibrium quickly, whereas poorly soluble compounds would take longer time. Calcium Acetate dissolves readily, hence the equilibrium reaches quickly. Calcium Acetate binds more than $90 \%$ at above $\mathrm{pH}$ 6.0. Hence the phosphate buffer solutions were selected at range of $0.02817 \mathrm{mM}$ and $5.6334 \mathrm{mM}$. The buffer solutions $\mathrm{pH}$ ranges were found to be around 10.0 and 11.5 respectively. The pHs of the same solutions were observed 7.0 and 8.5 after dissolving the Calcium Acetate tablets in the mentioned phosphate buffers. Calcium acetate binding drops to $0 \%$ at lower $\mathrm{pH}(\mathrm{pH} 3.5)$, this happens because at low $\mathrm{pH}$, where hydrogen ion concentration is high, $\mathrm{H}^{+}$competes for phosphorus more effectively than calcium [24].

In the experiment $0.0 \mathrm{mM}$ phosphate buffer is nothing but deionised water, basically no binding and complete calcium to be found in the analysis and zero free phosphorus to be expected. The increase in the phosphate concentration resulted binding and expected less free phosphorus and the other hand free calcium was decreased since calcium was bounded to phosphate and formed as calcium phosphate. At maximum precipitation concentration of $5.6334 \mathrm{mM}$ free calcium decreased significantly since feasibility of maximum binding. The phosphate binding assay versus phosphate concentration was figured in Figure 5.

\section{Conclusions}

A validated and accurate ICP-OES method has been de- veloped to estimate calcium and phosphorus in In vitro phosphate binding study of Eliphos tablets. The method is selective and is capable of quantitate calcium and phosphorus in the presence of other trace elements. The method has been validated in terms of specificity, precision, linearity, accuracy and limit of quantification. The validated method can be used to estimate calcium and phosphorus in In vitro studies of not only Eliphos tablets, any generic version of calcium acetate tablets. The In vitro experiment was done using the validated method on Eliphos tablets and results are in good agreement with theoretical assumption. The benefit of the study is to use an alternate In vitro method to estimate the binding capacity of calcium acetate tablets to avoid the expensive in-vivo bio clinical studies.

\section{Acknowledgements}

The authors wish to thank Dr. Sudhakar Rao, president of Invagen pharmaceutical Inc. for supporting this work. We would also like to thank colleagues in analytical department of Invagen pharmaceutical Inc. for their

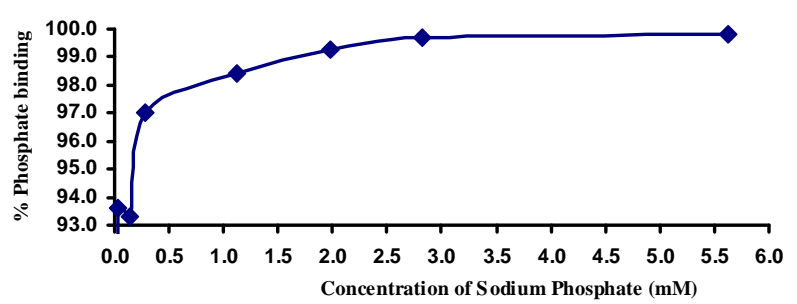

Figure 5. Graph plotted for percentage phosphate binding of Eliphos tablets. Percentage phosphate binding on Y-axis and different concentrations of sodium phosphate buffer on $\mathrm{X}$-axis. 
co-operation in carrying out this work.

\section{References}

[1] J. J. Schucker and K. E. Ward, "Hyperphosphatemia and Phosphate Binders," American Journal of Health-System Pharmacy, Vol. 62, No. 22, 2005, pp. 2355-2361. doi:10.2146/ajhp050198

[2] M. R. Kaplan, C. L. Stashenko, A. L. Bledsoe and J. McGowan, "Calcium Acetate Tablets versus Gelcaps in Hemodialysis Patients," Nephrology Nursing Journal, Vol. 29, No. 4, 2002, pp.

[3] S. V. Verstraeten, L. Aimo and P. I. Oteiza, "Aluminum and Lead: Molecular Mechanisms of Brain Toxicity," Archives of Toxicology, Vol. 82, No. 11, 2008, pp. 789802. doi:10.1007/s00204-008-0345-3

[4] A. T. Proudfoot, "Aluminum and Zinc Phosphide Poisoning," Clinical Toxicology, Vol. 47, No. 2, 2009, pp. 89-100. doi:10.1080/15563650802520675

[5] A. C. Alfrey, G. R. Le Gendre and W. D. Kaehny, “The Dialysis Encephalopathy Syndrome. Possible Aluminum Intoxication," New England Journal of Medicine, Vol. 294, No. 4, 1976, pp. 184-188. doi:10.1056/NEJM197601222940402

[6] D. Drago, A. Cavaliere, N. Mascetra, et al., “Aluminum Modulates Effects of Beta Amyloid (1-42) on Neuronal Calcium Homeostasis and Mitochondria Functioning and Is Altered in a Triple Transgenic Mouse Model of Alzheimer's Disease,” Rejuvenation Research, Vol. 11, No. 5, 2008, pp. 861-871. doi:10.1089/rej.2008.0761

[7] S. W. Bihaqi, M. Sharma, A. P. Singh and M. Tiwari, "Neuroprotective Role of Convolvulus Pluricaulis on Aluminum Induced Neurotoxicity in Rat Brain,” Journal of Ethnopharmacology, Vol. 124, No. 3, 2009, pp. 409-415. doi:10.1016/j.jep.2009.05.038

[8] H. M. Bolt and J. G. Hengstler, “Aluminum and Lead Toxicity Revisited: Mechanisms Explaining the Particular Sensitiveity of the Brain to Oxidative Damage," Archives of Toxicology, Vol. 82, No. 11, 2008, pp. 787-788. doi:10.1007/s00204-008-0366-y

[9] C. Exley, L. Swarbrick, R. K. Gherardi and F. J. Authier, "A Role for the Body Burden of Aluminum in Vaccine-Associated Macrophagic Myofasciitis and Chronic Fatigue Syndrome,” Medical Hypotheses, Vol. 72, No. 2, 2009, pp. 135-139.

doi:10.1016/j.mehy.2008.09.040

[10] E. Gilbert-Barness, L. A. Barness, J. Wolff and C. Harding, "Aluminum Toxicity," Archives of Pediatrics \& Adolescent Medicine, Vol. 152, No. 5, 1998, pp. 511-512.

[11] A. Becaria, A. Campbell and S. C. Bondy, "Aluminum as a Toxicant,” Toxicology \& Industrial Health, Vol. 18, No.

\section{7, 2002, pp. 309-320. doi:10.1191/0748233702th157oa}

[12] C. B. Boss and K. J. Fredeen, “Concepts, Instrumentation and Techniques in Inductively Coupled Plasma Optical Emission Spectrometry," 3rd Edition, Perkin Elmer, Waltham, 1997.

[13] P. W. J. M. Boumans, "Inductively Coupled Plasma Emission Spectroscopy-Part 2,” In: P. J. Elving and J. D. Winefordner, Eds., Chemical Analysis, John Wiley \& Sons, New York, Vol. 90, 1987.

[14] M. K. Stamatakis, J. M. Alderman and P. J. Meyer-Stout, "Influence of $\mathrm{pH}$ on in Vitro Disintegration of Phosphate Binders,” American Journal of Kidney Diseases, Vol. 32, No. 5, 1998, pp. 808-812. doi:10.1016/S0272-6386(98)70137-4

[15] S. M. Kobrin, S. J. Goldstein, R. F. Shangraw, R. M. Raja, "Variable Efficacy of Calcium Carbonate Tablets," American Journal of Kidney Diseases, Vol. 14, 1989, pp. 461-465.

[16] C. J. Carr and R. F. Shangraw, "Nutritional and Pharmaceutical Aspects of Calcium Supplementation,” American Pharmaceutical, Vol. NS27, No. 2, 1987, pp. 149-157.

[17] N. A. Mason, J. D. Patel, J. B. Dressman and L. A. Shimp, "Consumer Vinegar Test for Determining Calcium Disintegration," American Journal of Hospital Pharmacy, Vol. 49, No. 9, 1992, pp. 2218-2222.

[18] M. S. Sheikh, J. A. Maguire, M. Emmett, C. A. St. Ana, M. J. Nicar, L. R. Schiller and J. S. Fordran, "Reduction of Dietary Phosphorus Absorption by Phosphorus Binders," Journal of Clinical Investigation, Vol. 83, No. 1, 1989, pp. 66-73. doi:10.1172/JCI113886

[19] A. Montaser and D. W. Golightly, "Inductively Coupled Plasma in Analytical Atomic Spectrometry,” 2nd Edition, VCH Publishers, Inc., New York, 1992

[20] M. Thompson and J. N. Walsh, "A Handbook of Inductively Coupled Plasma Spectrometry,” Blackie, Glasgow, 1983.

[21] D. A. Skoog, F. J. Holler and T. A. Nieman, "Principles of Instrumental Analysis,” 5th Edition, Thomson Asia Pte Ltd., Singapore City, 2005.

[22] G. R. Chatwal and S. K. Anand, "Atomic and Molecular Spectroscopy," 5th Edition, Himayala Publishing House Pvt. Ltd., Mumbai, 2010.

[23] Federal Register, “Definitions and Terminology," ICH Draft Guidelines on Validation of Analytical Procedures, IFONA, Vol. 60, 1995, 11260.

[24] M. S. Sheikh, J. A. Maguire, M. Emmett, C. A. St. Ana, M. J. Nicar, L. R. Schiller and J. S. Fordtran, "Reduction of Dietary Phosphorus Absorption by Phosphorus Binders," Journal of Clinical Investigation, Vol. 83, No. 1, 1989, pp. 66-73. doi:10.1172/JCI113886 